\title{
The effect of blowing or suction on laminar free convective heat transfer on flat horizontal plates
}

\author{
H. J. H. Brouwers, Enschede, The Netherlands
}

\begin{abstract}
In the present paper laminar free convective heat transfer on flat permeable horizontal plates is investigated. To assess the effect of surface suction or injection on heat transfer a correction factor, provided by the film model (or "film theory"), is applied. Comparing the film model predictions with numerical results of previous boundary layer analyses yields good agreement for a wide range of dimensionless transpiration levels.
\end{abstract}

Der Einfluß von Ausblasung oder Absaugung auf den Wärmeübergang an ebenen horizontalen Platten bei laminarer freier Konvektion

Zusammenfassung: In der Arbeit wird der Wärmeübergang an ebene stoffdurchlässige horizontale Platten bei laminarer freier Konvektion untersucht. Zur Abschätzung des Einflusses von Absaugung oder Ausblasung auf den Wärmeübergang wird ein aus der Filmtheorie entnommener Korrekturfaktor herangezogen. Ein Vergleich der Voraussagen nach dem Filmmodell mit vorliegenden numerischen Ergebnissen nach dem Grenzschichtmodell ergab gute Übereinstimmungen in einem weiten Bereich des dimensionslosen Transpirationsgrades.

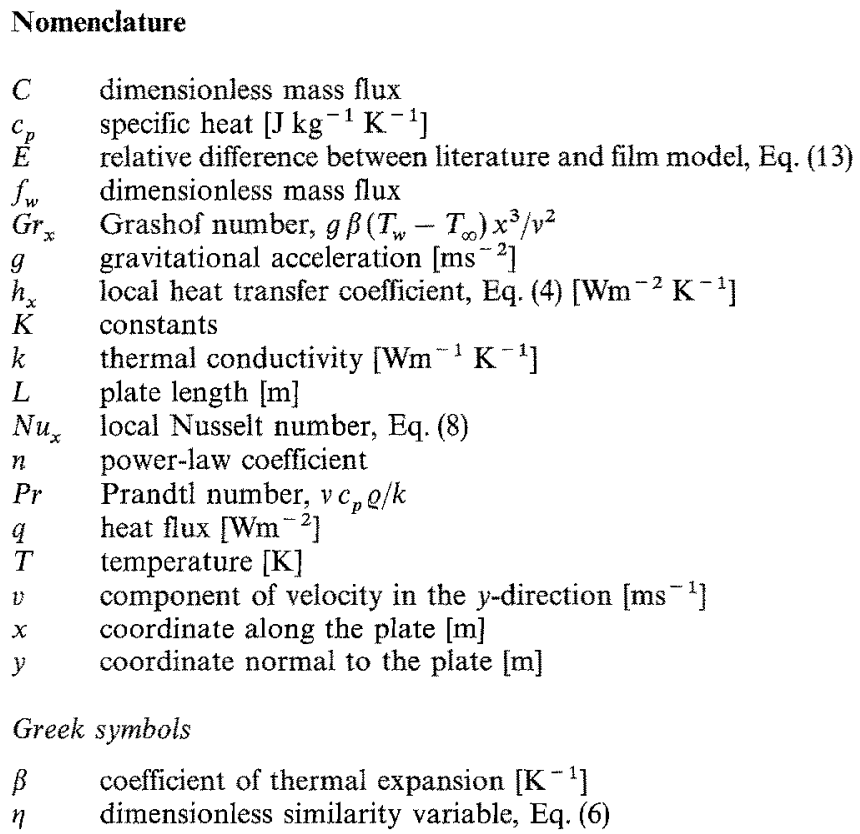

$\Theta_{t}$ ratio of actual heat transfer and impermeable plate heat transfer

$\Theta \quad$ dimensionless temperature, Eq. (5)

$v \quad$ kinematic viscosity $\left[\mathrm{m}^{2} \mathrm{~s}^{-1}\right]$

g density $\left[\mathrm{kg} \mathrm{m}^{-3}\right]$

$\phi_{t}$ dimensionless wall mass flux, Eq. (3)

Subscripts

film pertaining to film model

num pertaining to numerical solution

$w \quad$ wall

$\infty \quad$ ambient fluid

Superscripts

* pertaining to impermeable plate differentiation with respect to $\eta$ mean

\section{Introduction}

Free convection flows over horizontal flat plates are encountered in many practical applications, for instance heat transfer from/to ceilings or floors. The flow along and heat transfer to impermeable plates have been studied by Stewartson [1], Gill et al. [2], Rotem and Claassen [3], Goldstein et al. [4], Jones [5], Pera and Gebhart [6] and Umemura and Law [7]. The effect of surface injection or suction have been studied by Clarke and Riley [8, 9], Afzal and Hussain [10], Lin and Yu [11] and Ramanaiah et al. [12].

The effect of wall transpiration on heat transfer can also be assessed with the help of the classical film model. This model provides analytical expressions, the so-called correction factors, which can be applied to any system of importance. In the past these film model correction factors have been successfully used to predict the effect of surface mass transfer on transport phenomena, such as heat transfer. The correction factors can be derived analytically from a simple stagnant film analysis and applied to systems using either an imposed (transpiration) wall mass flux or a diffusional vapour mass flux (by condensation or evaporation). Recent reviews of the film model are found in Bannwart [13], Bann- 
wart and Bontemps [14], Brouwers [15] and Brouwers and Chesters [16].

To the author's knowledge, the film model has never been applied to free convective heat transfer between a permeable horizontal wall and a fluid. In the present analysis the film theory correction for the effect of wall transpiration on heat transfer, the so-called Ackermann factor, is applied to this problem. Subsequently, the predictions of the compact film model are thoroughly compared with the numerical suction results of Hussain [17], who proceeded from the physical model presented in Afzal and Hussain [10], and suction and injection results of Ramanaiah et al. [12].

\section{Film model}

According to the film theory the actual local heat transfer, denoted by $q_{w}$, in the presence of mass transfer follows from multiplying the zero suction (or neutral) $q_{w}^{*}$ by a correction factor:

$q_{w}=\Theta_{t, \mathrm{film}} q_{w}^{*}$.

The thermal correction factor, commonly referred to as Ackermann correction, follows from e.g. [16] as:

$\Theta_{t, \mathrm{film}}=\frac{-\phi_{i}}{e^{-\phi_{t}}-1}$

where the dimensionless mass flux towards the wall reads:

$\phi_{t}=-\frac{v_{w} \varrho c_{p}}{h_{x}^{*}}$

In this equation $h_{x}^{*}$ represents the local heat transfer coefficient in the case of zero mass transfer which is defined as:

$h_{x}^{*}=\frac{q_{w}^{*}}{T_{\infty}-T_{w}}=\frac{\left.k \frac{d T}{d y}\right|_{y=0} ^{*}}{T_{\infty}-T_{w}}$,

where $y$ is a coordinate normal to the plate.

Using

$\Theta(\eta)=\frac{T-T_{\infty}}{T_{w}-T_{\infty}}$,

$\eta=\frac{y}{x} G r_{x}^{1 / 5}$,

Eq. (4) yields:

$h_{x}^{*}=-\frac{k \Theta^{\prime}(0)^{*}}{x} G r_{x}^{1 / 5}$,

where the prime represents differentiation with respect to $\eta$. Following $[1,2] \Theta^{\prime}(0)$ amounts to -0.3574 for free convective heat transfer between an isothermal horizontal plate and a fluid with $\operatorname{Pr}=0.72$. If the local Nusselt number is defined as:

$N u_{x}=\frac{x h_{x}}{k}$ one obtains as neutral Nusselt number correlation:

$N u_{x}^{*}=0.3574 G r_{x}^{1 / 5}$.

It is interesting to note that for free convective heat transfer to a vertical isothermal plate Ostrach [18] obtained:

$N u_{x}^{*}=0.5046 G r_{x}^{1 / 4}$,

for $\operatorname{Pr}=0.72$.

From Eqs. (1)-(3) and Eq. (7) it can readily be concluded that, following the film model, the effect of a surface mass flux on heat transfer can be assessed in a relatively simple way.

\section{Comparison with previous work}

The film model correction for the effect of mass transfer on heat transfer is compared with the results of $[10,12,17]$. References $[10,17]$ concern a boundary layer analysis of laminar free convective flow over a horizontal isothermal plate with imposed suction. Ramanaiah et al. [12] present a study of both suction and injection.

References $[10,12,17]$ considered power-law variations of the wall temperature $\left(T_{\mathrm{w}}-T_{\infty}=K_{1} x^{n}\right)$ and the transpiration velocity $\left(v_{w}=K_{2} x^{(n-2) / 5}\right)$ under which self-similar solutions of the governing equations are possible. For various dimensionless wall suction parameters, denoted by $C$ in $[10$, 17] and by $f_{w}$ in [12], the dimensionless temperature gradient at the wall, $-\Theta^{\prime}(0)$, were determined numerically. The heat transfer ratio now readily follows as:

$\frac{q_{w}}{q_{w}^{*}}=\frac{\Theta^{\prime}(0)}{\Theta^{\prime}(0)^{*}}=\Theta_{t, \mathrm{num}}$,

which can be compared with the film model correction factor. To this end, the dimensionless mass flux $\phi_{t}$ has to be assessed. This property is related to $C$ by:

$\phi_{i}=-\frac{C(n+3) \operatorname{Pr}}{5 \Theta^{\prime}(0)^{*}}$,

see Eqs. (3) and (7), and equation (36) from [10]. For $n=0$ and $\operatorname{Pr}=0.72$ values of $\Theta^{\prime}(0)$ were computed by [17], using the model of [10], as a function of various $C$. These values are summarized in Table 1. A glance at this table shows that $\Theta^{\prime}(0)^{*}$ amounts to -0.3571 . This value is in agreement with the value provided by $[1,2]$, mentioned in the previous section. Furthermore, it is also in accordance with the value provided in $[3] ; \Theta^{\prime}(0)^{*}$ (referred to as " $H^{\prime}(0)$ ") equals -0.35909 there.

Table 1 includes both the pertaining film model correction factors and the relative error defined as:

$E=\frac{\Theta_{t, \text { film }}-\Theta_{t, \text { num }}}{\Theta_{t, \text { num }}}$.

The tabulated values of $E$ indicate that for suction, i.e. $C>0$ and $\phi_{t}>0$, the film model predictions well correspond to the 
Table 1. The effect of wall suction on heat transfer according to Hussain [17] and the film model ( $T_{w}$ is constant)

\begin{tabular}{llllll}
\hline Hussain [17] & Eq. (11) & Eq. (12) & Eq. (2) & Eq. (13) \\
\cline { 1 - 1 }$C$ & $-\Theta^{\prime}(0)$ & $\Theta_{t, \text { num }}$ & $\phi_{t}$ & $\Theta_{t, \text { fimm }}$ & \multicolumn{1}{l}{$E$} \\
\hline 0.0 & 0.3571 & 1.0000 & 0.0000 & 1.0000 & $0.0 \%$ \\
1.0 & 0.6186 & 1.7323 & 1.2097 & 1.7239 & $-0.5 \%$ \\
2.0 & 0.9380 & 2.6267 & 2.4195 & 2.6558 & $-1.1 \%$ \\
3.0 & 1.3220 & 3.7020 & 3.6292 & 3.7281 & $-0.7 \%$ \\
4.0 & 1.7376 & 4.8659 & 4.8390 & 4.8390 & $-0.5 \%$ \\
\hline
\end{tabular}

Table 2. The effect of wall transpiration on heat transfer according to Ramanaiah et al. [12] and the film model ( $T_{w}$ is constant)

\begin{tabular}{|c|c|c|c|c|c|}
\hline \multicolumn{2}{|c|}{ Ramanaiah et al. [12] } & \multirow{2}{*}{$\begin{array}{l}\text { Eq. (11) } \\
\Theta_{t, \text { num }}\end{array}$} & \multirow{2}{*}{$\begin{array}{l}\text { Eq. (16) } \\
\phi_{t}\end{array}$} & \multirow{2}{*}{$\begin{array}{l}\text { Eq. (2) } \\
\Theta_{t, \text { film }}\end{array}$} & \multirow{2}{*}{$\begin{array}{l}\text { Eq. (13) } \\
E\end{array}$} \\
\hline$f_{w^{\prime}}$ & $-\Theta^{\prime}(0)$ & & & & \\
\hline-1.0 & 0.1786 & 0.4997 & -1.2087 & 0.5145 & $3.0 \%$ \\
\hline 0.0 & 0.3574 & 1.0000 & 0.0000 & 1.0000 & $0.0 \%$ \\
\hline 1.0 & 0.6121 & 1.7126 & 1.2087 & 1.7232 & $0.6 \%$ \\
\hline
\end{tabular}

Table 3. The effect of wall transpiration on heat transfer according to Ramanaiah et al. [12] and the film model ( $q_{x}$ is constant)

\begin{tabular}{|c|c|c|c|c|c|}
\hline \multicolumn{2}{|c|}{ Ramanaiah et al. [12] } & \multirow{2}{*}{$\begin{array}{l}\mathrm{Eq} \cdot(11) \\
\Theta_{i, \text { num }}\end{array}$} & \multirow{2}{*}{$\begin{array}{l}\text { Eq. (16) } \\
\phi_{t}\end{array}$} & \multirow{2}{*}{$\begin{array}{l}\text { Eq. (2) } \\
\Theta_{t, \mathrm{fitm}}\end{array}$} & \multirow{2}{*}{$\begin{array}{l}\text { Eq. (13) } \\
E\end{array}$} \\
\hline$f_{w}$ & $-\Theta^{\prime}(0)$ & & & & \\
\hline-1.0 & 0.2749 & 0.5959 & -1.0405 & 0.5684 & $-4.6 \%$ \\
\hline 0.0 & 0.4613 & 1.0000 & 0.0000 & 1.0000 & $0.0 \%$ \\
\hline 1.0 & 0.7201 & 1.5610 & 1.0405 & 1.6089 & $3.1 \%$ \\
\hline
\end{tabular}

Table 4. The effect of wall transpiration on heat transfer according to Ramanaiah et al. [12] and the film model ( $v_{w}$ is constant)

\begin{tabular}{cccccc}
\hline Ramanaiah et al. [12] & Eq. (11) & Eq. (16) & Eq. (2) & Eq. (13) \\
\cline { 1 - 2 }$f_{w}$ & $-\Theta^{\prime}(0)$ & $\Theta_{t, \text { num }}$ & \multicolumn{1}{l}{$\phi_{t}$} & $\Theta_{t, \text { film }}$ & $E$ \\
\hline-1.0 & 0.4894 & 0.6498 & -0.9560 & 0.5970 & $-8.1 \%$ \\
0.0 & 0.7531 & 1.0000 & 0.0000 & 1.0000 & $0.0 \%$ \\
1.0 & 1.0995 & 1.4600 & 0.9560 & 1.5530 & $6.4 \%$ \\
\hline
\end{tabular}

numerical results. For larger suction rates the deviation initially increases, but subsequently the film model and numerical predictions converge again. In the following it is explained that the film model prediction and asymptotic solution (as derived in [10]) for large suction rates are equivalent indeed.

Combining equations (22) and (24) of [10] yields:

$q_{w}=\left.\frac{d T}{d y}\right|_{y=0}=\frac{\left(T_{w}-T_{\infty}\right) \operatorname{Pr}}{v}$, as expression for the heat transfer in the case of large suction. Eqs. (3), (4) and (14) produce:

$q_{w}=\phi_{t} q_{w}^{*}$.

For large suction Afzal and Hussain [10] thus obtained this asymptotic relation between actual (permeable plate) heat flux and neutral (impermeable plate) heat flux. A glance at the film model correction factor in Eq. (2) shows that $\Theta_{t}$ also tends to $\phi_{t}$ for large $\phi_{t}$. So the fact that the results of [10] and the film model converge for very large suction rates is in fact no surprise.

From Eqs. (3), (7), and equation (16) of [12] one can relate $\phi_{t}$ and $f_{w}$ by:

$\phi_{t}=-\frac{f_{w}(n+3) P r}{5 \Theta^{\prime}(0)^{*}}$.

For $P r=0.72$, and $n=0$ (constant $\left.T_{w}\right), n=1 / 3$ (constant $q_{w}$ ) and $n=2$ (constant $v_{w}$ ) values of $\Theta^{\prime}(0)$ were computed for $f_{w}=-1,0$ and 1 . The numerical results of [12] and the predictions of the film model are presented in Tables $2-4$.

The negative $f_{w}$ of these tables corresponds to injection, while positive $f_{w}$ corresponds to suction. Comparing Tables 1 and 2 reveals that the impermeable plate results $\left(C=f_{w}=0\right)$ and suction results $\left(C=f_{w}=1\right)$ of $[10,17]$ are in agreement with those of [12]. Furthermore, in all cases Tables 1-4 illustrate the substantial effect of suction/injection on heat transfer, as well the good agreement between film model and numerical similarity solutions.

For purely forced convective heat transfer along a permeable plate Mickley et al. [19] obtained a comparable agreement between the boundary layer analysis, the film model and performed experiments. As the film model provides adequate predictions for both purely free and purely forced convective heat transfer, it is expected that the predictions are reliable for the intermediate case of mixed convection along a horizontal permeable plate as well.

\section{Mean heat transfer}

In the foregoing the attention has been focused on the effect of mass transfer on local heat transfer coefficients. In what follows the effect on mean heat transfer coefficients is analyzed in some detail.

The mean neutral heat transfer coefficient is defined as:

$\tilde{q}=\frac{1}{L} \int_{x=0}^{L} q_{w} d x$.

In case of no mass transfer, substitution of Eqs. (4) and (7) transforms Eq. (17):

$\bar{q}^{*}=-\frac{5 k \Theta^{\prime}(0)^{*}}{3 L} G r_{L}^{1 / 5}\left(T_{\infty}-T_{w}\right)$

For convection with mass transfer, i.e. $\Theta_{t, \text { film }} \neq 1$, the integral of Eq. (17) can be solved in closed form too, since $\phi_{i}$ and hence $\Theta_{t, \text { film }}$, are constant, see Eqs. (1)-(2) and (12). This feature of constant $\phi_{t}$ (and $C$ or $f_{w}$ ) is a result of the imposed 
similarity solution. Hence, the mean heat transfer then simply follows from multiplying the mean neutral heat transfer, governed by Eq. (18), by the - constant - film model correction factor.

\section{Conclusions}

In this paper the film model has been applied to free convective heat transfer in the presence of mass transfer. The film model correction factor for heat transfer has been extensively compared with existing theoretical results of Afzal and Hussain [10, 17] and Ramanaiah et al. [12]. These elaborations involved a laminar free convective boundary layer flow over a porous horizontal plate. In these studies the governing equations were derived and solved numerically by imposing a similarity solution, the Prandtl number being set equal to 0.72 .

For a wide range of transpiration levels the film model appeared to agree within a few per cent with the results of the literature. Furthermore, it was proved that for infinitely large suction the film model correctly predicts the asymptotic behaviour of the process. Hence, one can conclude that the basic film model is well suited to describe the effect of transpiration on free convective heat transfer to horizontal flat permeable plates.

\section{Acknowledgements}

The author wishes to express his thanks to Professor H. van Tongeren, for his encouragement of this work, and the Cornelis Lely Foundation for their financial support.

\section{References}

1. Stewartson, K.: On the free convection from a horizontal plate. Z. Angew. Math. Phys. 9 a (1958) 276-282

2. Gill, W. N., Zeh, D. W; Del Casal, E.: Free convection on a horizontal plate. Z. Angew. Math. Phys. 16 (1965) 539-541

3. Rotem, Z; Claassen, L.: Natural convection above unconfined horizontal surfaces. J. Fluid Mech. 38 (1969) 173-192

4. Goldstein, R. J.; Sparrow, E. M.; Jones, D. C.: Natural convection mass transfer adjacent to horizontal plates. Int. J. Heat Mass Transfer 16 (1973), 1025-1035
5. Jones, D. R.: Free convection from a semi-infinite plate inclined at a small angle. Quart. J. Mech. Appl. Math. 26 (1973) 77-78

6. Pera, L.; Gebhart, B.: Natural convection boundary layer flow over horizontal and slightly inclined surfaces. Int. J. Heat Mass Transfer 16 (1973) 1131-1146

7. Umemura, A.; Law, C. K.: Natural-convection boundary-layer flow over heated plate with arbitrary inclination. J. Fluid Mech. 219 (1990) 571-584

8. Clarke, J. F.; Riley, N.: Natural convection induced in a gas by the presence of a hot porous horizontal surface. Quart. J. Mech. Appl. Math. 28 (1975) 373-396

9. Clarke, J. F; Riley, N.: Free convection and the burning of a horizontal fuel surface. J. Fluid Mech. 74 (1976) 415-431

10. Afzal, N.; Hussain, T.: Effects of large suction in natural convection boundary layer on a horizontal plate. Wärme- Stoffübertrag. 20 (1986) 203-206

11. Lin, H. T., Yu, W. S.: Free convection on a horizontal plate with blowing and suction. J. Heat Transfer 110 (1988) 793-796

12. Ramanaiah, G.; Malarvizhi, G.; Merkin, J. H.: A unified treatment of mixed convection on a permeable horizontal plate. Wärme- Stoffübertrag. 26 (1991) 187-192

13. Bannwart, A. C.: Etude théoretique et expérimentale de la condensation d'une vapour en présence d'incondensables. Thèse de Doctorat, Institut National Polytechnique de Grenoble (1988) (in French)

14. Bannwart, A. C.; Bontemps, A.: Condensation of a vapour with incondensables: an improved gas phase film model accounting for the effect of mass transfer on film thicknesses. Int. J. Heat Mass Transfer 33 (1990) 1465-1474

15. Brouwers, H. J. H.: Film models for transport phenomena with fog formation, with application to plastic heat exchangers and condensers. Ph.D. Thesis, Eindhoven University of Technology (1990)

16. Brouwers, H. J. H,; Chesters, A. K.: Film models for transport phenomena with fog formation: the classical film model. Int. J. Heat Mass Transfer 35 (1992) 1-11, 2067

17. Hussain, T.: Private communications, KDM Institute of Petroleum Exploration, Dehradun 248195, India (1991)

18. Ostrach, S.: An analysis of laminar free convection flow and heat transfer about a flat plate parallel to the direction of the generating body force, NACA Techn. Note 2635 (1952) or NACA Rep. 1111 (1953)

19. Mickley, H. S.; Ross, R. C.; Squyers, A. L.; Stewart, W. E.: Heat, mass, and momentum transfer for flow over a flat plate with blowing or suction. NACA Techn. Note 3208 (1954).

Dr. H. J. H. Brouwers

Dept. of Civil Engineering \& Management

University of Twente

P.O. Box 217

7500 AE Enschede

The Netherlands

Received March 13, 1992 